\title{
Biological activity of the mite Sancassania sp. (Acari: Acaridae) from bat guano associated with the pathogenic fungus Histoplasma capsulatum
}

\author{
Daniel A Estrada-Bárcenas', José G Palacios-Vargas², Edith Estrada-Venegas ${ }^{3}$, Pavel B Klimov , \\ Alejandro Martínez-Mena ${ }^{2}$, Maria Lucia Taylor ${ }^{1 /+}$
}

1Departamento de Microbiología-Parasitología, Facultad de Medicina ²Departamento de Biología, Facultad de Ciencias, Universidad Nacional Autónoma de México, Ciudad Universitaria, 04510 México DF, México ${ }^{3}$ Instituto de Fitosanidad, Colegio de Posgraduados, Montecillo, Texcoco, Mexico ${ }^{4}$ Museum of Zoology, University of Michigan, Michigan, USA

Mites and the mammal pathogenic fungus Histoplasma capsulatum are the major components of bat guano microbiota. Interactions between mites and $\mathrm{H}$. capsulatum were evaluated under laboratory conditions. Acarid mites, mainly Sancassania sp., were the most abundant microarthropod in the sampled guano of the Mexican bat Tadarida brasiliensis mexicana and, based on its morphology, Sancassania $s p$. was similar to the cosmopolitan species Sancassania sphaerogaster. The mycophagous and vectoring activities of this mite were tested for $\mathrm{H}$. capsulatum and two other fungal species, Sporothrix schenckii (pathogenic) and Aspergillus sclerotiorum (non-pathogenic). S. ca. sphaerogaster was able to reproduce in $\mathrm{H}$. capsulatum and $\mathrm{S}$. schenckii colonies, multiplying in great numbers under controlled fungal mycelial-phase culture conditions. H. capsulatum colonies were completely destroyed after 14 days of in vitro interaction with mites. In contrast, S. ca. sphaerogaster did not reproduce in A. sclerotiorum cultures. $\mathrm{S}$. ca. sphaerogaster was found vectoring $\mathrm{H}$. capsulatum, but not the two other fungal species studied.

Key words: mites - Sancassania sp. - Histoplasma capsulatum - bat guano

Bat guano sustains a diverse microbiota, including insects, mites, bacteria and fungi. Among mites, the cohort Astigmatina (Suborder: Oribatida) includes mites inhabiting various terrestrial and aquatic habitats, often forming remarkable associations with their invertebrate and vertebrate hosts (Palacios-Vargas 2001). Most astigmatid mites from guano are involved in decomposing organic matter, such as the family Acaridae, including pests of stored products, cultivated and wild mushrooms and fungal colonies in laboratory collections (Hoffmann 1998). This family contains the ubiquitous genus Sancassania, which has also been reported as mycophagous and found in guano of different caves from Mexico, mainly located in the states of Morelos and Guerrero (Hoffmann et al. 1986).

The mycophagous activity of mites has been associated with contamination of fungal culture collections, as described for various genera of Astigmata (cohort: Astigmatina) and Prostigmata (Smith \& Onions 1994); however, Sancassania has never been cited as a pest in micromycete culture collections. Several astigmatid mites show a broad food preference for macromycetes (Okabe \& OConnor 2001, Klimov \& OConnor 2003, Kheradmand et al. 2007). Acarid mites may also be important vectors of fungal spores in indoor mushroom commercial units (Okabe 1999).

Financial support: Science Graduate Program - UNAM, CONACyT (98268 to DAE-B)

+Corresponding author: emello@servidor.unam.mx

Received 8 August 2009

Accepted 12 January 2010
The ecological niche of the mammalian pathogenic fungus Histoplasma capsulatum var. capsulatum is related to naturally accumulated bird and bat guano. In this environment, the fungus grows as a mycelial-phase producing aerosolised infective forms (mainly microconidia and hyphal fragments) that, once inhaled by susceptible hosts, can produce an infection with a variable clinical course, including the systemic histoplasmosis disease (Tewari et al. 1998, Taylor et al. 2000). In general, the most frequent source of infection is found in bat guano located in enclosed places, such as grottos, caves, mines and abandoned buildings. There is a dynamic and complex food web in this habitat, where the "trophic levels" are occupied by different organisms in a food chain, including arthropods (such as mites) and fungi (such as $H$. capsulatum). To date, no interactions between mites and H. capsulatum in this unique environment have been recorded.

The aim of the present paper is to report the in vitro interactions between mites and the pathogenic fungus $H$. capsulatum, as both organisms share the same microhabitat (bat guano) of a particular ecological niche in a Mexican cave.

\section{MATERIALS AND METHODS}

Guano - Samples of Tadarida brasiliensis mexicana (Russell et al. 2005) guano were collected in the "La Boca" cave, located in the municipality of Santiago, in the state of Nuevo León, Mexico. This cave is a shelter for a colony of approximately 5 million of these insectivorous bats. Guano samples were collected at $30 \mathrm{~m}$ from the cave's entry. The temperature and relative humidity of the cave environment were $37^{\circ} \mathrm{C}$ and $70-80 \%$, respectively. Guano samples were placed in different $100 \mathrm{~mL}$ plastic bottles $\left(11 \mathrm{~cm}^{3}\right.$ of guano/sample) until filling each 
one and the bottles were then transported to and kept in the laboratory under controlled conditions (darkness at $4^{\circ} \mathrm{C}$ without preservation solutions that could interfere with mites' survival) before processing. Ten samples from five well-defined sites in the cave were collected.

Mites - Mites were separated from the bat guano using Berlese funnels and placed on Petri dishes with a charcoal-plaster base. Then, mites were screened with a stereoscopic microscope Olympus SD30 (Olympus American Inc, US) and photographed with a Sony DSCW70/SC E33 digital camera (Sony Corporation, China). Mite specimens were preserved in $70 \%$ alcohol and later mounted in Hoyer's solution, as described by PalaciosVargas and Mejía-Recamier (2007). Mite gender and ontogenetic stage (adult, nymph and larvae) were determined by chaetotaxy and morphological characters in the laboratory. Mite identification was based on Lindquist et al. (2009). Species identification from the Acaridae family was conducted by Dr. Pavel B Klimov (Museum of Zoology, University of Michigan, MI, USA).

Live mites were maintained on charcoal-plaster Petri dishes incubated at $28^{\circ} \mathrm{C}$ in conditions of darkness and cultured in mycobiotic-agar (Bioxón, México DF) supplemented with commercial yeast $(0.2 \mathrm{~g})$ spread on the mycobiotic-agar surface, until use.

\section{In vitro biological interaction between mites and fungi}

Mycophagous activity - Three live mite specimens (2 females and 1 male), selected based on their abundance in guano samples, were placed on separate Petri dishes, each containing different fungal species previously reported in bat guano (Ulloa et al. 1998, 2006). Mycobiotic slant cultures of 4-week-old H. capsulatum (pathogenic) and two other micromycetes fungi, either 1-week-old Sporothrix schenckii (pathogenic) or Aspergillus sclerotiorum (non-pathogenic) were used for a set of triplicate assays. H. capsulatum strain (EH-53) was isolated from a patient infected in a cave in the state of Hidalgo, Mexico. It belongs to the "Histoplasma capsulatum Strain Collection of the Fungal Immunology Laboratory of the Department of Microbiology-Parasitology, Faculty of Medicine, National Autonomous University of Mexico", which is registered in the World Data Centre for Microorganisms database with the acronym LIHUNAM WDCM817 (http://histoplas-mex.unam.mx).

Mites placed on sterile mycobiotic-agar, water-agar and potato-agar (Bioxón) served as a control without fungal cultures. These cultures were observed with a stereoscopic microscope every three days to record mite life cycles and every week to register their abundance. The mites were photographed with a digital camera (Sony) and were counted in four optical fields. The means of triplicate assays were recorded. The mycophagous activity of mites was documented using a digital video camera Sony Handycam DCR-PC109 (Sony) adapted to a stereoscopic microscope Zeiss Stemi SV6 MC 80 DX (Zeiss, Oberkochen, Germany).

Vectoring activity - To document possible fungal phoresy on mite species, mites were harvested individually from each culture of pathogenic fungi, where they were able to develop after 2-3 weeks of incuba- tion at $28^{\circ} \mathrm{C}$. Two types of assays, involving four mite specimens for each replicate, were conducted: (i) mites were decapitated and immediately placed on mycobiotic slants and (ii) before killing, mites were washed for $30 \mathrm{~s}$ with three different cleaning solutions $(10 \%$ chloride, $70 \%$ ethanol and sterile distilled water) to eliminate fungal structures on the mite cuticle and then placed on mycobiotic slants.

All procedures were performed under sterile conditions. During incubation $\left(2-4\right.$ weeks at $\left.28^{\circ} \mathrm{C}\right)$, mycobiotic slants were observed daily to detect fungal growth. Colonies compatible with fungal morphotypes associated with the mite inoculum were documented after their cloning in mycobiotic slants and identification by macro and micromorphology. Each assay was performed in triplicate.

\section{RESULTS}

Mite abundance in guano - One thousand three hundred eighty-seven microarthropods, representing 21 taxa belonging to Arachnida, Acari (mites), Collembola and Insecta, were found. Mites were the most diverse and included 14 morphospecies with 1,365 specimens in four orders: Sarcoptiformes [Astigmatina (72.2\%) and Brachypylina (4.2\%)], Ixodida [Ixodoidea (0.2\%)], Mesostigmata [Monogynaspida (5.4\%)] and Trombidiformes [Prostigmata (18\%)]. Collembola included four morphospecies with 12 specimens belonging to three orders: Entomobryomorpha, Poduromorpha and Neelipleona. Insecta included two morphospecies with nine specimens in two orders: Coleoptera and Diptera. Pseudoescorpionida was the less abundant taxon, with one morphospecies with only one specimen. Astigmatina predominated in the guano samples, emphasising that Sancassania sp. (57\% of all microarthropod specimens collected) was the most abundant.

From the microarthropods collected, only two orders, Mesostigmata and Sarcoptiformes, were maintained alive in the laboratory. Two species of Mesostigmata (one and two specimens each) and two of Sarcoptiformes, which consisted of one species of the cohort Brachypylina (with one specimen) and one species of the cohort Astigmatina (with six specimens of the Sancassania sp.) were processed for in vitro biological interaction assays with fungi.

Interactions between mites and fungi - Before assessing in vitro biological interactions between mites and fungi, two species of Mesostigmata, one of Brachypylina and one of Astigmatina, were reared in separate plates containing mycobiotic medium supplemented with commercial yeast (see Materials and Methods).

Mite development on colonies of $H$. capsulatum or $S$. schenckii was monitored for 5-25 days. The presence of adults, nymphs and larvae was detected only on plates containing the Sancassania sp. (Astigmatina), indicating that reproduction of the mite took place. Fig. 1A-C shows Sancassania sp. growing on $H$. capsulatum and Fig. 1D-F on $S$. schenckii fungal cultures. Although a few Mesostigmata survived on $H$. capsulatum cultures for a short time, they were unable to reproduce and 
eventually died, as did Brachypylina. Mites placed on cultures of $A$. sclerotiorum survived for 10 days and no ontogenetic stages were found (data not shown). Based on its morphology, the Sancassania species that was found to be associated with bat guano and reproduction on $H$. capsulatum or $S$. schenckii colonies is similar to the cosmopolitan species Sancassania sphaerogaster (Astigmatina: Acari: Acaridae).

Mycophagous activity of $S$. ca. sphaerogaster was well-demonstrated, as shown in a video animation (see details under Materials and Methods and Supplementary data). The absolute destruction of the $H$. capsulatum colony was observed after its infestation with $S$. ca. sphaerogaster. Alterations in colony macromorphology were visually detected. Three to 10 days after mite infestation, the border of fungal colonies presented remarkable changes with progressive destruction (Fig. 2A-C). After 14 days, these colonies were seriously damaged and destroyed by mite feeding activity. Regarding the $S$. schenckii colonies, destruction by the mites was less evident. In contrast, no mite reproduction occurred in other assays using $A$. sclerotiorum colonies and uncultured media (mycobiotic-agar, water-agar and potato-agar).

The maximum number of mites registered per assay at 12-13 days after fungal culture infestation was 80 on $H$. capsulatum, followed by 40 and 30 mites on $S$. schenckii mycobiotic-agar and potato-agar cultures, respectively.

The kinetics of mite abundance with regard to the infestation time on fungal cultures is shown in Fig. 3. The means of three sets of assay show that the highest abundance was found at days 12-13 on $H$. capsulatum mycobiotic-agar cultures, followed by day 18 on $S$. schenckii mycobiotic-agar cultures. In contrast, in the assays with $A$. sclerotiorum, the three mite specimens initially placed on the fungal cultures only remained alive for five days (Fig. 3).

In relation to the vectoring activity, out of 12 specimens of $S$. ca. sphaerogaster sampled from H. capsulatum cultures, only eight were associated with fungal

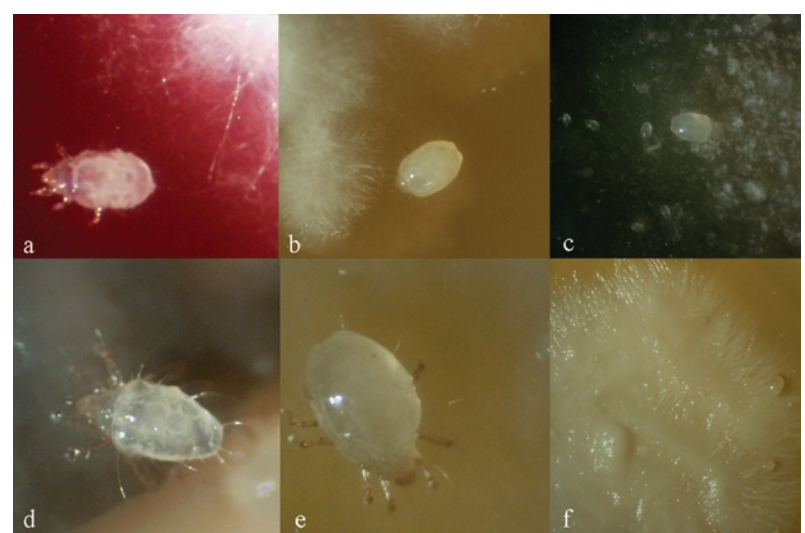

Fig. 1: adults, nymphs and larvae of mites grown on fungal plate cultures. a-c: Sancassania sp. grown on Histoplasma capsulatum culture: a: nymph; b: female; c: larvae, nymphs and females; d-f: Sancassania sp. grown on Sporothrix schenckii culture: d: male; e: female; f: adults.

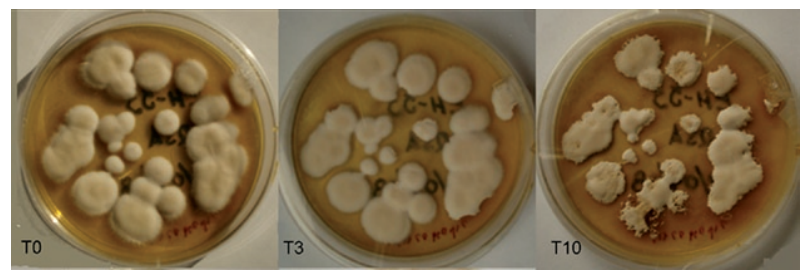

Fig. 2: macromorphological changes in Histoplasma capsulatum colonies infested with Sancassania ca. sphaerogaster. T0: immediately after infestation; T3: after three days; T10: after 10 days.

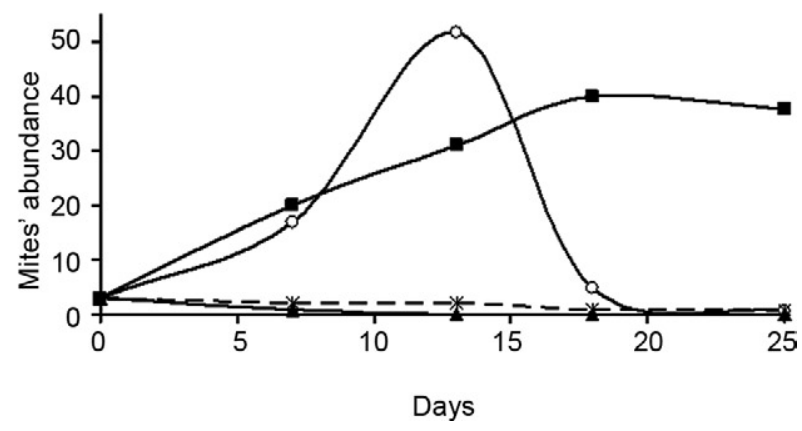

Fig. 3: abundance of Sancassania ca. sphaerogaster in different fungal cultures. Alive mites were placed in Petri dishes containing fungal species that had been cultured on mycobiotic slants. Mites were counted every three days. The plotted data represent the means of triplicate assays, until the 25th day (details under Materials and Methods). - - : Histoplasma capsulatum; - -: Sporothrix schenckii;- $\mathbf{\Delta - :}$ Aspergillus sclerotiorum; - X-: mycobiotic-agar (uncultured control).

colonies in the new culture plates (see details in Material and Methods). These colonies shared a macromorphology compatible with $H$. capsulatum. After cloning on fresh culture media, the fungal micromorphology was observed and the typical conidia of $H$. capsulatum were identified. Assays performed with S. schenckii were all negative. Assays performed with mites washed with different solutions (see Materials and Methods) showed no fungal growth after being observed for four weeks. In most cases, plates also exhibited bacterial contaminations.

\section{DISCUSSION}

$S$. ca. sphaerogaster was the most abundant mite in the guano from "La Boca" cave, representing $57 \%$ of all sampled microarthropods in this habitat. Some species of this genus have become specialised in feeding on basidiomycetes (Okabe \& OConnor 2001, Klimov \& OConnor 2003), while other species are generalists and may feed on a variety of substrates, including fungi (Kheradmand et al. 2007). Several genera of Acaridae are mycophagous and are reared on macromycetes culture (Okabe 1993, 1999) and some of them have even been reported to be pests of micromycetes: Acarus siro, Histiogaster sp., Rizoglyphus robini, Rizoglyphus echinopus, Schwiebea sp., Tyrophagus putrescentiae (Rivard 1961, Noble \& Poe 1973, Yamada 1974, Price 1976, Okabe 1993, 1999, Smith \& Onions 1994, Okabe \& OConnor 2001). 
In the "La Boca" cave environment, the mycobiota associated with bat guano could favour the development of Sancassania by providing the food necessary for its survival; however, no data were found showing that the diet of this mite is exclusively restricted to fungi. Most probably, Sancassania is a generalist in terms of food preference.

In the laboratory, the rearing of different species of Mesostigmata, Brachypylina and Astigmatina was attempted, using fungal culture as food source. However, only an Astigmatina, identified as $S$. ca. sphaerogaster, was able to reproduce. Sancassania poses serious challenges for identification due to its high morphological variability and the lack of a comprehensive review. To ensure $S$. ca. sphaerogaster species, sequences of the mitochondrial gene $\mathrm{COI}$ and the nuclear ribosomal gene 28SD9-10 will be processed.

$S$. ca. sphaerogaster developed its life cycle preferentially on $H$. capsulatum cultures and showed a maximum population size at 15 days after fungal culture infestation (Fig. 3), causing complete destruction of H. capsulatum colonies in 2-3 weeks. This suggests that the $H$. capsulatum mycelial-phase supplies the optimal requirements for $S$. ca. sphaerogaster development. Controls of uncultured media did not favour mite reproduction, suggesting that different medium components, by themselves, did not favour mite growth. S. ca. sphaerogaster is not specific for $H$. capsulatum, as it also grew on $S$. schenckii cultures. However, changes in the macromorphology of S. schenckii colonies were less remarkable, even though the number of mites remained constant for a long time, suggesting that mites consume this fungus in a non-preferential manner (Fig. 3). It is difficult to explain why $S$. ca. sphaerogaster was unable to reproduce on A. sclerotiorum. This could be because this fungal species does not provide the necessary dietary requirements for the mite, or some mycotoxins, known from Aspergillus (Lazo \& Sierra 2008), might be involved.

The abundance of $S$. ca. sphaerogaster in bat guano indicates that this mite species could be considered a primary consumer in the guano food web. Based on the present findings, $S$. ca. sphaerogaster may be viewed as a potential natural biological control for H. capsulatum, since it shares the same environmental microhabitat and effectively destroys the fungus under laboratory conditions.

Vectoring activity mediated by $S$. ca. sphaerogaster was demonstrated for $H$. capsulatum cultures, indicating that a short-range dispersion of $H$. capsulatum may occur on $S$. ca. sphaerogaster in natural conditions. The mite cuticle is probably involved in this dispersal, since successive washes of mites using cleaning solutions eliminated fungal structures and, consequently, fungal growth was not detected. The absence of phoresy of $S$. schenckii on $S$. ca. sphaerogaster is probably related to the moistness of this fungal colony together with its leathery and wrinkled surface, which did not favour attachment of $S$. schenckii structures to the mite cuticle.

This is the first report on the interactions between the mite $S$. ca. sphaerogaster and the mammal pathogenic fungus $H$. capsulatum.

\section{ACKNOWLEDGEMENTS}

To Ingrid Mascher, for editorial assistance.

\section{REFERENCES}

Hoffmann A 1998. Los ácaros asociados a hongos, su papel en la naturaleza. Rev Inst Nal Enf Resp Mex 11: 183-186.

Hoffmann A, Palacios-Vargas JG, Morales-Malacara JB 1986. Manual de bioespeleología, con nuevas aportaciones para Morelos y Guerrero, México, Dirección General de Publicaciones, Universidad Nacional Autónoma de México, México DF, 274 pp.

Kheradmand K, Kamali K, Fathipour Y, Goltapeh EM, Ueckermann EA 2007. Thermal requirement for development of Sancassania rodionovi (Acari: Acaridae) on mushrooms. J Econ Entomol 100: 1098-1103.

Klimov PB, OConnor BM 2003. Phylogeny, historical ecology and systematics of some mushroom-associated mites of the genus Sancassania (Acari: Acaridae) with new generic synonymies. Invert System 17: 469-514.

Lazo RF, Sierra G 2008. Investigación del efecto de las micotoxinas en el ser humano. Rev Iberoam Micol 25: 7-11.

Lindquist EE, Krantz GW, Walter DE 2009. Classification. In GW Krantz, DE Walter, A manual of acarology, Texas Tech University Press, Lubbock, p. 97-103.

Noble WE, Poe SL 1973. Attractancy of several fungi and bacteria for bulb and soil mites frequenting diseased gladiolus corms. Proc Fla State Hort Soc 85: 401-404.

Okabe K 1993. Population growth and dispersal behavior of Histiogaster sp. (Acari: Acaridae) on several economically important fungi. Appl Entomol Zool 28: 11-18.

Okabe K 1999. Vectoring of Hypocrea nigricans (Hypocreales: Hypocreaceae) by three fungivorous mite species (Acari: Acaridae). Exp Appl Acarol 23: 653-658.

Okabe K, OConnor BM 2001. A method for both mass and individual rearing of fungivorous mites (Acari). Exp Appl Acarol 25: 493-504.

Palacios-Vargas JG 2001. La biodiversidad de los ácaros cavernícolas en México. In M Vargas, OJ Polaco, G Zúñiga, Contribuciones entomológicas. Homenaje a la Dra. Isabel Bassols Batalla, Escuela Nacional de Ciencias Biológicas-IPN, México DF, p. 105-112.

Palacios-Vargas JG, Mejía-Recamier BE 2007. Técnicas de colecta, preservación y montaje de microartrópodos, Las Prensas de Ciencias, Universidad Nacional Autónoma de México, México $\mathrm{DF}, 74 \mathrm{pp}$.

Price DW 1976. Passage of Verticillium albo-atrum propagules through the alimentary canal of the bulb mite. Phytopathology 66: 46-50.

Rivard I 1961. Influence of temperature and humidity on longevity, fecundity and rate of increase of the mite Tyrophagus putrescentiae (Schrank) (Acarina: Acaridae) reared on mold cultures. Can J Zool 39: 869-876.

Russell AL, Medellin RA, McCracken GF 2005. Genetic variation and migration in the Mexican free-tailed bat (Tadarida brasiliensis mexicana). Mol Ecol 14: 2207-2222.

Smith D, Onions AHS 1994. The preservation and maintenance of living fungi. IMI Technical Handbooks 2, 2nd ed., CAB International, Wallingford, $122 \mathrm{pp}$.

Taylor ML, Reyes-Montes MR, Chávez-Tapia CB, Curiel-Quesada E, Duarte-Escalante E, Rodríguez-Arellanes G, Peña-Sandoval GR, Valenzuela-Tovar F 2000. Ecology and molecular epidemiology findings of Histoplasma capsulatum, in Mexico. In RM 
Mojan, M Benedik, Research advances in microbiology, Global Research Network, Kerala, p. 29-35.

Tewari R, Wheat LJ, Ajello L 1998. Agents of histoplasmosis. In L Ajello, RJ Hay, Medical mycology. Topley \& Wilson's, Microbiology and microbial infections, Arnold and Oxford University Press Inc, New York, p. 373-407.

Ulloa M, Lappe P, Aguilar S, Park H, Pérez-Mejía A, Toriello C, Taylor ML 2006. Contribution to the study of the mycobiota present in the natural habitats of Histoplasma capsulatum: an integrative study in Guerrero, Mexico. Rev Mex Biodiver 77: 153-168.

Ulloa M, Lappe P, Aguilar S, Pérez-Mejía A, Toriello C, Taylor ML 1998. Hongos filamentosos asociados con el hábitat natural de Histoplasma capsulatum en Guerrero, México. Rev Inst Nal Enf Resp Mex 11: 173-182.

Yamada K 1974. Role of the bulb mite on disease development of bulb rot of Tulip. Kinki Chugoku Agr Res 48: 77-81. 